\title{
Álcool e Drogas: Um problema vivido por adolescentes Usuários em um Município do Sudoeste da Bahia
}

\author{
Luana Alves Lobo ${ }^{1}$; Mirella Cristina Leto Babosa ${ }^{2}$
}

\begin{abstract}
Resumo: O presente estudo aborda sobre o problema de adolescentes usuários de drogas de um município do sudoeste da Bahia, analisando as consequências e causas que levam os adolescentes a serem usuários de drogas. Nota-se que o período da adolescência é fundamental para o desenvolvimento humano, em que acontece uma busca pela idade adulta, pois há o abandono das características físicas e identidade infantis, desenvolvimento de sua autonomia, aderindo formas mais independentes dos seus progenitores, com acentuada procura pela identidade própria, nesta fase os questionamentos são muito presentes e é comum que o adolescente siga um caminho levado pelas más influências, como o das drogas. Neste sentido a assistência a este público é necessária e deve ser constante já que, há carência de atendimento para esta população especial, além da necessidade de novos estudos nesse âmbito. Observa-se que embora 65,6\% destaquem, que na escola deles há preocupação com jovens que usam drogas, 41,4\% são jovens deste ambiente que utilizam tal sustância, 96,5\% já presenciaram uso de drogas licitas, e 44,8\% de drogas ilícitas. Dos entrevistados 10,3\% já experimentaram algum tipo de droga ilícita e 34,3\% fazem uso de drogas licitas, ressaltando que, $98,2 \%$ já receberam orientação para não usar drogas. Contudo percebeu-se o quão a realidade das drogas é alarmante devido ao alto índice de usuários em idade entre 12 e 20 anos, necessitando de mais medidas de combate em prol de erradicar esse problema nas escolas.
\end{abstract}

Palavras-chave: Usuários de Drogas, Adolescentes, Assistência.

\section{Alcohol and Drugs: A problem experienced by adolescents users in a Southwest Municipality at Bahia}

\begin{abstract}
The present study deals with the problem of adolescent drug users in a city in southwestern Bahia, analyzing the consequences and causes that lead adolescents to be drug users. It is noted that the adolescence period is fundamental for human development, in which a search for adulthood occurs, since there is the abandonment of physical characteristics and infantile identity, development of its autonomy, adhering more independent forms of its parents, with marked Search for the identity itself, at this stage the questions are very present and it is common for the adolescent to follow a path taken by bad influences, such as drugs. In this sense assistance to this public is necessary and must be constant since there is a lack of care for this special population, in addition to the need for further studies in this area. It is observed that, although $65.6 \%$ say that in their school there is concern about young people who use drugs, $41.4 \%$ are youngsters of this environment who use this substance, $96.5 \%$ have already witnessed the use of legal drugs, and $44,8 \%$ of illicit drugs. Of those interviewed, $10.3 \%$ had tried some type of illicit drug and $34.3 \%$ had used legal drugs, noting that $98.2 \%$ had already been advised not to use drugs. However, the reality of drugs is alarming due to the high rate of users between the ages of 12 and 20, and it needs more combat measures to eradicate this problem in schools.
\end{abstract}

Keywords: Drug Users, Adolescents, Care.

\footnotetext{
${ }^{1}$ Graduanda em enfermagem pela Faculdade Independente do Nordeste - FAINOR. Vitoria da Conquista - BA. E-mail: luanaloboenf@hotmail.com

${ }^{2}$ Docente no curso de enfermagem e odontologia na Faculdade Independente do Nordeste - FAINOR. Vitoria da Conquista- BA.

E-mail: mirellaleto@fainor.com.br
} 
Id on Line Revista Multidisciplinar e de Psicologia

Id on Line Multidisciplinary and Psycology Journal

\section{Introdução}

A prática de ingerir drogas vem de longa data, bem antes da antiguidade, muitos homens já se intoxicavam sistematicamente, houve viciados em drogas muito antes de existirem agricultores. É válido salientar que, conforme descritos de épocas mais remotas, na maioria das vezes a droga era usada como remédio, ou seja, para diminuir o sofrimento das pessoas. Muitos a usavam para esquecer a fome que sentiam, uma vez que algumas drogas diminuem o apetite, enquanto dura seu efeito (GIKOVATE, 2002).

As drogas ativam o sistema de recompensa do cérebro, provocando neste e no usuário um tipo de ilusão química de prazer que o induz, a continuar a usá-las. E a partir daí que surge a dependência química, que se caracteriza como a repetição do consumo, a pessoa passa a prezar apenas pelo prazer imediato propiciado pela droga, mesmo que isso comprometa e ameace sua vida (FIGLIE, 2004).

O uso de drogas e a dependência química são sem dúvida um dos principais problemas do mundo cotidiano, e o seu uso por adolescentes e até crianças, vem se tornando um dos maiores problemas sociais da atualidade, principalmente no que diz respeito ao uso das drogas lícitas, como o cigarro e o álcool, vez que este consumo é bem maior, já que esses jovens encontram o aspecto da facilidade, pois tais drogas são de mais fácil acesso, baixo custo, e ainda contam com o estimulo e publicidade da mídia, que por sua vez, vem a editar o que é moda, “legal” (AUTURES, 2007).

Levando em consideração que a adolescência é uma fase de escolhas, modificações e afirmação da identidade onde o indivíduo está mais sujeito as induções de ideias externas, é importante destacar que esta época da vida é uma "divisora de águas" e deve servir para auxiliar na formação do intelecto da pessoa de forma correta, para a partir daí, esta se tornar uma pessoa madura e com conceitos bons que vão ajudá-la por toda a sua vida adulta (FREDA, 2010).

Algumas pesquisas realizadas pelo CEBRID (Centro Brasileiro de Informações sobre Drogas Psicoativas (PSA,s) abordam que as Substâncias Psicoativas mais consumidas são o tabaco, álcool, os inalantes, maconha, cocaína e crack, onde o início do uso tem se apresentado mais precocemente na faixa dos 12 anos (FIGLIE, 2004). 
Id on Line Revista Multidisciplinar e de Psicologia

Id on Line Multidisciplinary and Psycology Journal

A adolescência se torna uma etapa da vida onde requer muita cautela e atenção no processo do desenvolvimento humano por ser uma fase de independência e auto afirmação. Torna-se muito mais acessível aos jovens que tiveram em sua vivencia familiar problemas com omissão e negligência, sem uma formação moral e ética que serviram como base para a entrada no mundo do crime, transformando-os em pessoas que desconhecem limites, buscando realizações e satisfações de desejos imediatos sem que passem por critérios de avaliação e geralmente percebem as consequências somente após a ocorrência dos fatos.

A questão da droga é complexa e inclui muitos fatores. Não se pode negar que tensões familiares são desagradáveis e geram muitos malefícios, sobretudo na época da infância e da adolescência. Entretanto, cada indivíduo reage de forma particular às experiências concretas do mundo. Deve-se considerar o lugar específico que cada um ocupa na dinâmica familiar para poder, assim, se aproximar das reais motivações do seu consumo.

O uso de drogas é um mal que afeta a sociedade atual, que influência o tráfico e a criminalidade, destruindo famílias e deixando jovens sem uma perspectiva de vida. Deste modo esse estudo busca enfatizar que deve ser dada uma atenção especializada aos adolescentes usuários em prol da saúde dos mesmos e assim, essa análise foi feita com uma amostra de adolescentes de um município do Sudoeste da Bahia, analisando a questão dos usuários de drogas e álcool nas escolas da cidade.

A prática de ingerir drogas vem de longa data, mas busca-se averiguar o envolvimento dos adolescentes com esse produto, problematizando a relação dos adolescentes nas escolas acerca do uso de álcool e outras drogas. Diante disso a pesquisa vem demonstrar os problemas que envolvem os jovens que fazem uso de álcool e outras drogas que estudam em um colégio no município de sudoeste da Bahia.

\section{Metodologia}

Trata-se de uma pesquisa exploratória-descritiva que segundo Gil (2010) pretende proporcionar maior familiaridade com o tema de modo a explicitá-lo. Tida ainda como uma pesquisa qualitativa, com caráter descritivo, cujo objetivo primordial a descrição das 
Id on Line Revista Multidisciplinar e de Psicologia

Id on Line Multidisciplinary and Psycology Journal

características de determinadas população ou fenômenos ou, então, o estabelecimento de relação entre variáveis.

A pesquisa foi realizada com adolescentes envolvidos com drogas em um município do sudoeste da Bahia, tendo como local de estudo mais especificamente um colégio estadual de ensino médio deste município. A população do estudo foram adolescentes envolvidos com situação de uso de drogas e álcool, através de um levantamento de dados a partir da aplicação de questionário (pesquisa de campo) no colégio, onde estudam 369 alunos, destes, participaram do estudo 58 alunos, e deste grupo 29 que estudam no turno matutino e 29 do turno vespertino.

Salienta-se ainda que todos os participantes foram informados a respeito dos objetivos do estudo através de termo de consentimento esclarecido, obedecendo às recomendações da Resolução n466/2012 do Conselho Nacional de Saúde (BRASIL, 2002b)

\section{Resultados e Discussões}

Na Tabela 1, constam-se os dados de idade dos 58 entrevistados, todos, estudantes do colégio do município do sudoeste da Bahia, englobando alunos de dois turnos. Nota-se que com reação a idade todos estão entre a faixa etária de 12 a 20 anos de idade, dividida conforme o seguinte percentual infra mencionado:

Tabela 1:Distribuição dos dados referentes a idade dos participantes

\begin{tabular}{lll}
\hline Idade & $\mathrm{N}$ & $\%$ \\
\hline 12 a 14 anos & 15 & 25,8 \\
15 a 17 anos & 31 & 53,6 \\
18 a 20 anos & 12 & 20,6 \\
Total & $\mathbf{5 8}$ & $\mathbf{1 0 0}$ \\
\hline
\end{tabular}

Fonte: Dados do questionário utilizado na pesquisa.

O Estatuto da Criança e do Adolescente- ECA traz uma definição sobre a criança e adolescente, baseado no fator biológico como estruturante, associando à faixa etária a fase de desenvolvimento humano. Então a criança está enquadrada entre 0 e 12 anos, e o adolescente 
entre 12 e 18 anos, frisando ainda que é uma condição peculiar de pessoa em desenvolvimento, adotando desta forma uma concepção psicossocial (BRASIL, 1990).

No análise em questão, a adolescência se configura como fases do desenvolvimento, cujo fator biológico é estruturante, e as relações sociais, por assim dizer que o "fazer" com o outro reflete na definição que temos (LEPRE, 2003).

Com relação a idade e o uso de drogas, nota-se que a adolescência é uma fase que deixa os indivíduos mais expostos, devido a rebeldia, curiosidade e grande influência de amizades em seu cotidiano. Vasters e Pillon (2011)alertam para necessidade de estudar o uso de drogas na adolescência devido aos prejuízos ocasionados precocemente aos que fazem uso de substâncias deste tipo, primando por ações preventivas e de combate a essa realidade alarmante.

A tabela 2 a seguir demonstra a distribuição relacionada a tais aspectos relacionados a relação dos participantes da pesquisa com as drogas, destacando a intimidade que tem com tal situação:

Tabela 2. Distribuição dos dados referente ao álcool e Drogas

\begin{tabular}{lll}
\hline Variáveis & $\mathrm{N}$ & $\%$ \\
\hline Preocupação da escola com jovens usuários & 38 & 65,6 \\
$\quad$ Sim & 20 & 34,4 \\
Não & & \\
Conhecimento sobre jovens usuários/ escola & 24 & 41,4 \\
$\quad$ Sim & 34 & 58,6 \\
Não & & \\
Já presenciou consumo de drogas licitas & 56 & 96,5 \\
$\quad$ Sim & 2 & 3,5 \\
Não & & \\
Já presenciou consumo de drogas ilícitas & 26 & 44,8 \\
Sim & 32 & 55,2 \\
Não & & \\
Já experimentou drogas ilícitas & 6 & 10,3 \\
Sim & 52 & 89,7 \\
Não & & 34,4 \\
Consome drogas licitas & 20 & 65,6 \\
Sim & 38 & 20,6 \\
Não & & 79,4 \\
Utiliza drogas com frequência & 12 & $\mathbf{1 0 0}$ \\
$\quad$ Sim & 46 & \\
Não & $\mathbf{5 8}$ & \\
Total & & \\
\hline
\end{tabular}

Fonte: Dados do questionário utilizado na pesquisa. 
Id on Line Revista Multidisciplinar e de Psicologia

Id on Line Multidisciplinary and Psycology Journal

Nota-se que embora 65,6\% destacam que na escola deles há preocupação com jovens que usam drogas. Mas mesmo com tal atitude de preocupação no ambiente escolar notada pela maioria dos jovens, $41,4 \%$ destes conhecem jovens deste ambiente que utilizam tal sustância.

Neste contexto, Fonseca (2006) destaca que o consumo de drogas atualmente ameaça à estabilidade das estruturas e valores econômicos, políticos, sociais e culturais e no grupo jovem, conforme levantamento epidemiológico feiro no Centro Brasileiro de Informações sobre Drogas Psicotrópicas (CEBRID), em estudantes de educação básica, é comum a presença de psicotrópicos em ambiente escolar, inclusive em idades mais precoces.

A falta de modelo de identificação propicia uma alquimia própria guiada pela busca do autocontrole das sensações na adolescência, na tentativa de resolver sozinho os próprios problemas (MOREIRA et al, 2008), inclusive as angustias existenciais, por exemplo, alguns bebem para relaxar e, se ficam "de porre", "cheiram"(cocaína) para "levantar o moral" e, ao final da jornada, entre outras situações que os fazem se tornar dependentes (FREDA, 2010).

Ainda com relação aos dados da pesquisa nota-se que há uma diferença entre drogas licitas e ilícitas, na qual as primeiras são drogas legalizadas (cigarro, álcool, por exemplo) e as ilícitas são as proibidas por lei a venda e consumo. Neste contexto, esta pesquisa aferiu que 96,5\% já presenciaram uso de drogas licitas, e 44,8\% de drogas ilícitas, 10,3\% já experimentaram algum tipo de droga ilícita e 34,3\% fazem uso de drogas licitas.

Nota-se o quão a realidade das drogas é alarmante, as drogas licitas já se inseriram na sociedade como a coisa mais normal e está presente em lares e em todos grupos sociais. Estudo feito que analisou a relação de adolescentes com drogas licitas e ilícitas destaca a imersão das drogas licitas e ilícitas em seus contextos familiar, escolar, comunitário e da mídia, sendo estes separados como âmbitos que ajudam a prevenir (geralmente família e escola) com outros que são de risco (mídia, amigos) (ALHEIT; DAUSIEN, 2006).

Monteiro et al (2003) aborda que o uso de drogas lícitas e ilícitas são um fenômeno de ordem social, que é frequente e gera prejuízos à saúde, e com relação as drogas estas independente de serem lícitas ou ilícitas, desde medicamentos, álcool, até maconha, crack, etc, geram problemas no comportamento e saúde da pessoa. Portanto é alarmante o consumo mesmo de sustâncias que alteram o sistema psicomotor que são permitidas a venda. Pois como o uso e 
Id on Line Revista Multidisciplinar e de Psicologia

Id on Line Multidisciplinary and Psycology Journal

abuso de drogas vem se tornando comum em idades cada vez mais precoces é necessário alertar dos perigos de seu uso e das chances de dependência (ZEITOUNE, 2012).

O presente trabalho analisou acerca dos programas e políticas de prevenção imersos no cotidiano destes jovens, e elencou em quesitos conforme tabela 3 destacada:

Tabela 3. Distribuição dos dados referente aos projetos de prevenção ao álcool e drogas

\begin{tabular}{lll}
\hline Politicas preventivas sobre drogas & N & $\%$ \\
\hline Participou de algum programa de prevenção & 43 & 74,1 \\
Sim & 15 & 25,9 \\
Não & & \\
Conhece serviço de saúde especializado em & & \\
atendimento ao usuário dependente & 13 & 22,5 \\
Sim & 45 & 77,5 \\
Não & & \\
Já recebeu orientação sobre não usar drogas & 57 & 98,2 \\
Sim & 1 & 1,8 \\
Não & $\mathbf{5 8}$ & $\mathbf{1 0 0}$ \\
Total & & \\
\hline
\end{tabular}

Fonte: Dados do questionário utilizado na pesquisa.

Nota-se que a escola encontra-se diante de um novo problema desafiante e assim deve primar pela prevenção no enfrentamento do consumo de drogas entre estudantes, pois atuar antes que o problema se instale é a melhor e mais inteligente alternativa (ALVES, 2005).

Mediante as falas e discussões dos adolescentes nota-se que com relação a escola essa vem elaborando programas na prevenção contra drogas. Viu-se que 74,1 \% já participaram de algum programa de prevenção.

Mas com relação a se conhecem algum serviço de saúde especializado em atendimento ao usuário dependente, apenas $22,5 \%$ destacaram ter conhecimento, enquanto $77,5 \%$ não conhecem, demonstrando que a cidade analisada necessita de um serviço que abarque tal situação e que haja divulgação deste para que os jovens conheçam a sua existência ou ainda utilizem dele caso necessitem. 
Id on Line Revista Multidisciplinar e de Psicologia

Id on Line Multidisciplinary and Psycology Journal

Nota-se a necessidade de um trabalho de intervenção na atenção a saúde desta comunidade em favor dos adolescentes, evitando o uso de drogas, atuando na prevenção e no controle do uso dessas substâncias. Neste contexto Zeitoune (2012) destaca a necessidade de se priorizar políticas preventivas através de ações educativas e de conscientização com os jovens e a comunidade para que se esclareça dúvidas, e efetive uma política de prevenção com relação ao uso e abuso de drogas lícitas ou ilícitas (ZEITOUNE, 2012).

No caso da atuação com os usuários de drogas, o profissional que trabalhe com tal demanda não só deve ficar atento a produção do conhecimento, mas identificar os interesses da classe investigada, identificar às necessidades e demandas destes que passam por necessidades, devendo essa assistência servir de ferramenta social para inclusão e inserção destes adolescentes na sociedade civil (LARA, 2008).

Percebe-se que orientar para o não uso de drogas atualmente é uma realidade comum, no estudo analisado $98,2 \%$ disseram já ter recebido orientação sobre não usar drogas, destacando a família, a escola, a mídia, serviços e centros de saúde, igreja, e amigos como os meios propagadores deste alerta ai não uso, tal realidade evidencia que os alertas vem de forma interdisciplinar e que são importantes na conscientização do jovem.

Passeti (2008) reflete que educadores compartilham desafios semelhantes, e tem nos cuidados preventivos como ponto de encontro para enfrentá-los. Com isso a necessidade de fazer algo em torno dos problemas sociais que repercutem e implicam de forma negativa na vida deste público aqui discutido, devendo estar engajado no processo educacional de adolescentes e crianças desenvolvendo ações que melhorem essa questão social é crucial.

O grande desafio é possibilitar uma qualidade de vida social em um cenário cada vez sem horizontes frente às questões sociais. É necessário abraçar este conceito de uma forma que se consiga unir a escola, educadores e família. Essa discussão é parte dos rumos perseguidos pelo trabalho profissional contemporâneo que prima por efetivar soluções viáveis neste contexto ( FONSECA, 2006).

O educador Antônio Carlos Gomes da Costa, um dos idealizadores do Estatuto da Criança e do Adolescente, citado por Lara (2008) declara que a partir do momento em que as crianças ficam soltas na comunidade, há uma perda de referência em relação aos valores considerados importantes para o desenvolvimento de uma base sólida. Salientando que é 
Id on Line Revista Multidisciplinar e de Psicologia

Id on Line Multidisciplinary and Psycology Journal

necessário conscientizar os adolescentes acerca dos riscos através da educação com qualidade e zelo.

\section{Considerações Finais}

Esse tema apresenta relevância social, pois contribui para o aumento do debate acerca das Drogas e o seu uso na adolescência principalmente relacionado ao ambiente escolar. Com relação aos adolescentes nota-se que as drogas fazem parte de seu cotidiano, licitas ou ilícitas, mas que estes já vem sendo alertados dos riscos acerca do uso.

Outro risco está com relação a preocupação em exposição dos jovens ao mundo onde o uso das drogas é comum. Assim, este estudo serve de apoio para as ações preventivas com relação aos usuários, pois consegue analisar a situação local da cidade averiguada servindo de base para medidas em prol deste problema ser evitado.

Nota-se que políticas públicas em prol da prevenção do uso de drogas para o grupo jovem em particular é uma necessidade latente na sociedade e que deve ser fomentada pois a conscientização virá través de ações educativas que primem pelo em estar social.

Ainda como benefícios podem ser citados o conhecimento que esta pesquisa traz para os leitores do mesmo, sendo importante a discussão desta temática, por ter uma abordagem importante, que envolve a vida de muitas pessoas e deve ser discutida para que sirva de modelo para políticas públicas de prevenção e cuidado do problema.

\section{Referências}

ALHEIT, Peter; DAUSIEN, Bettina. Processo de formação e aprendizagens ao longo da vida. Educ. Pesqui. São Paulo, v. 32, n. 1, p. 177-197, Apr. 2006

ALVES, Vânia Sampaio. Um modelo de educação em saúde para o Programa Saúde da Família: pela integralidade da atenção e reorientação do modelo assistencial. Saúde, v.9, n.16, 2005.

AUTURES \& Agentes \& Associados. Drogas: Se eu quiser parar você me ajuda? Rio de Janeiro, FIA (Fundação Para a Infância e Adolescência), 2007. 
Id on Line Revista Multidisciplinar e de Psicologia

Id on Line Multidisciplinary and Psycology Journal

Lei 8069/1990: ECA- Estatuto da Criança e do Adolescente. Brasília, 2005

FIGLIE, Neliana Buzi. Aconselhamento em dependência química / Selma Bordin, Ronaldo Laranjeira - São Paulo: Roca, 2004.

FONSECA, Marília Saldanha da. Como prevenir o abuso de drogas nas escolas?. Psicol. Esc. Educ. (Impr.), Campinas, v. 10, n. 2, p. 339-341, Dec. 2006.

FREDA, F. H. Textos sobre Toxicomania e Alcoolismo: Organização e tradução. Equipe do CETAD, 2010

GIL, A. C. Como Elaborar Projetos de Pesquisa. $4^{\text {a }}$ Ed. São Paulo. Editora: Atlas, 2010, p.41.

GIKOVATE, Flávio. Drogas: opção de perdedor, São Paulo: Moderna, 2002.

LARA, Ricardo. A Produção do Conhecimento em Serviço Social: o mundo do trabalho em debate. 2008. 281 f. Tese (Doutorado) - Faculdade de História, Direito e Serviço Social, Universidade Estadual Paulista "Júlio de Mesquita Filho", Franca, 2008.

LEPRE, Rita Melissa. Adolescência e construção da identidade, $1^{a}$ edição. Rio de Janeiro. 2003.

MONTEIRO SS, VARGAS EP, REBELLO SM. Educação, prevenção e drogas: resultados e desdobramentos da avaliação de um jogo educativo. Educ Soc. 2003 ago; v. 24, n.83, p:65978 .

MOREIRA, T.M. M. et al. Conflitos vivenciados pelas adolescentes. Rev. esc. enferm. USP vol.42 no. 2. São Paulo Jun. 2008. Disponível em: $<$ http://www.scielo.br/scielo.php?script=sci_arttext\&pid=S0080-623420080002000 15\&l ng=en\&nrm=iso > Acesso em: 25 abr 2016.

PASSETI. Edson. O que é menor? $3^{\text {a }}$ Ed. Editora brasiliense. São Paulo, 2008.

VASTERS. Gabriela Pereira; PILLON. Sandra Cristina. O uso de drogas por adolescentes e suas percepções sobre adesão e abandono de tratamento especializado. Rev. Latino-Am. Enfermagem Artigo Original, v. 19, n. 2, mar-abr 2011.

ZEITOUNE, Regina Célia Gollner. O conhecimento de adolescentes sobre drogas lícitas e ilícitas: uma contribuição para a enfermagem comunitária. Esc. Anna Nery, Rio de Janeiro , v. 16, n. 1, p. 57-63, Mar. 2012.

Como citar este artigo (Formato ABNT): 
LOBO, L.A.; BARBOSA, M.C.L. Álcool e Drogas: Um problema vivido por adolescentes usuários em um Município do Sudoeste da Bahia. Id on Line Revista Multidisciplinar e de Psicologia, Janeiro de 2017, vol.10, n.33, p. 32-42. ISSN: 1981-1179.

Recebido: 23/11/2016

Aceito: $24 / 11 / 2016$ 